\title{
Library Growth and Academic Quality
}

\author{
By GEORGE PITERNICK
}

The late Fremont Rider's famous observations and conclusions on library growth $^{1}$ were re-examined in a recent article by $\mathrm{H}$. William Axford in this journal. ${ }^{2}$ Axford sought to find whether or not the growth of university libraries since 1946 was maintaining the pace Rider found typical for the period before 1940, and whether or not Rider's warning that libraries must double in size every fifteen or twenty years in order that their parent institutions might continue to maintain high academic rating is indeed valid. Axford found that university libraries, in the period 1946-1960, were not growing at a rate which would permit them to double in size every fifteen years, but at only 78 per cent of this rate. He concluded also that "Rider's emphasis on the relationship between the rate of growth of the university library and the over-all quality of the educational program is still essentially correct."'3 An examination, however, of the methods whereby Axford's data were chosen, used, and interpreted, may well lead to different conclusions and further questions.

It is regrettable that the study of library size and library growth rates is hampered by deficiencies in the quality of available library size and growth statistics. All libraries do not count their holdings in exactly the same way; neither do counting practices in a given library necessarily remain unchanged throughout its history. Progress in intermural

\footnotetext{
${ }^{1}$ Fremont Rider, "The Growth of American College and University Libraries - and of Wesleyan's" About Books at the Olin Library, Wesleyan University, XI (1940), 1-11.

${ }^{2}$ H. William Axford, "Rider Revisited," CRL, XXIII (1962), 345.47.

Ibid., p. 347 .
}

Mr. Piternick is Assistant Director of Libraries at the University of Washington, Seattle.

and intramural standardization has been and is being made; the benefits of each improvement in standardization can be felt, unfortunately, only in statistics generated subsequent to its adoption. Nevertheless, library size statistics, if worth gathering and publishing, are worth using - the degree to which conclusions may be invalidated by flaws in the data must, however, be always considered.

American university libraries whose holdings exceeded one million volumes by June 30,1960 , were used by Axford in his study of the first of Rider's axioms -that college and university libraries, on the average, double in size about every fifteen years. Axford's Table 1 illustrates the growth of each of these libraries in the period 1946-1960, expressing it as percentage increase during the period. Presumably a percentage increase of 100 during the period would constitute doubling. Several facts, however, complicate this simple comparison. For one thing, the interval is fourteen years instead of fifteen as Axford assumes. Second, the listed library holdings for 1946 are not internally consistent. Some are taken from the July 1947 issue of College and Research Libraries, others from the 1945 edition of the American Library Directory. The figures in the latter publication could apply to the year 1945 at the latest, and frequently refer to a date two or three years earlier. 
Third, the "average percentage increase" of 78 per cent, as printed, is an unweighted arithmetic average of individual percentages and hence of dubious relevance. Last, several errors in listing and computation are detectable.

Table 1 in this paper offers, in revised form, the growth characteristics of the academic libraries Axford selected for study for the period 1946 to 1960 . The holdings data for 1946 have been rationalized; they are taken from the July 1947 issue of College and Research $\mathrm{Li}$ braries, supplemented when necessary by data taken from the Princeton Statistics for College and University Libraries for 1945-1946. For each library, the average annual growth rate has been computed as has its corollary value, the doubling time. Doubling time is here used to represent the period of years necessary for a library's holdings to double at the average annual growth rate for the period studied. Table 1 also shows the growth characteristics of these libraries during the same number of years (fourteen) immediately preceding the dates of Axford's comparison period.

For the period 1946 to 1960, the libraries under study have grown at widely differing rates. Their mean growth rate during this period has been 20.1 years, which, to be sure, indicates a slowing down from Rider's average of fifteen years. However, there has been no perceptible slowing down in growth rate for these libraries over the previous period of fourteen years. Their mean doubling time between 1932 and 1946 was 20.7 years. Attention is again invited to the wide variation in individual growth rates.

In using this ranking as a gauge of over-all academic quality Axford, in his Table 2, did not rank the institutions according to the Keniston-Berelson rating as he intended, but instead in alphabetical order within two rank clusters used frequently by Berelson; top ten (with the addition of M.I.T. and CalTech) and second ten. Also, Axford's conclusion, as mentioned earlier, was evidently arrived at by inspection only.

But is Axford's sample typical? His libraries are, after all, the twenty-five largest university libraries, and therefore not likely typical of all university libraries. Moreover, Axford's sample is not identical with the sample upon which Rider based his conclusions, although there are many libraries common to both. A restudy of Rider's sample of twenty libraries (Table 2) shows that their growth rate has definitely decreased. His first group of ten "representative" large university libraries of respectable age he found to have had an average doubling time of sixteen years between 1831 and 1938. Their mean doubling time between 1938 and 1960 was 25.1 years. The second group of ten more recently founded university libraries he found to have grown at an average doubling time of 9.5 years (actually 10.9 years) between 1876 and 1938. Their average doubling time was twenty-two years between 1938 and 1960. Again, the individual variation is very large.

It appears, then, that any conclusions about the average growth rate of academic libraries must depend largely upon the libraries chosen for study, and the period during which their growth is studied. Certainly the variation in growth rates is very large. In the twentyfive libraries constituting Axford's sample we find doubling-time values ranging all the way from 9.3 years (UCLA, 1932-1946) to 43.7 years (Yale, 1946$1960)$.

That the growth in size of academic libraries is exponential rather than linear cannot be doubted. Or, put another way, it is clear that every library normally tends to add, during a given year, more volumes than it added during the preceding year and fewer than it will add the next year. It is not clear, how- 
TABLE 1

RECENT GROWTH OF UNIVERSITY LIBRARIES (after Axford, 1962)

\begin{tabular}{|c|c|c|c|c|c|c|c|c|c|c|c|c|c|}
\hline \multicolumn{6}{|c|}{ Library } & & \multirow{2}{*}{$\begin{array}{c}\begin{array}{c}\text { Holdings } \\
1932 \\
\text { (volumes) }\end{array} \\
3,341,700\end{array}$} & \multirow{2}{*}{$\begin{array}{c}\begin{array}{c}\text { Holdings } \\
1946 \\
\text { (volumes) }\end{array} \\
4,804,968\end{array}$} & \multirow{2}{*}{$\begin{array}{c}\begin{array}{c}\text { Average } \\
\text { Annual } \\
\text { Growth } \\
1932-46 \\
\text { (per cent) }\end{array} \\
2.6\end{array}$} & \multirow{2}{*}{$\begin{array}{c}\begin{array}{c}\text { Doubling } \\
\text { Time } \\
1932-46 \\
\text { (years) }\end{array} \\
27.0\end{array}$} & \multirow{2}{*}{$\begin{array}{c}\begin{array}{c}\text { Holdings } \\
1960 \\
\text { (volumes) }\end{array} \\
6,697,111\end{array}$} & \multirow{2}{*}{$\begin{array}{c}\begin{array}{c}\text { Average } \\
\text { Annual } \\
\text { Growth } \\
1946-60 \\
\text { (per cent) }\end{array} \\
2.4\end{array}$} & \multirow{2}{*}{$\begin{array}{c}\begin{array}{c}\text { Doubling } \\
\text { Time } \\
1946-60 \\
\text { (years) }\end{array} \\
29.2\end{array}$} \\
\hline Harvard & . & . & . & . & . & . & & & & & & & \\
\hline Yale . & . & . & . & . & . & . & $2,130,600$ & $3,539,596$ & 3.7 & 19.1 & $4,394,988$ & 1.6 & 43.7 \\
\hline Illinois & . & . & . & . & . & . & $1,113,733$ & $2,003,622$ & 4.3 & 16.5 & $3,288,158$ & 3.6 & 19.6 \\
\hline Columbia & 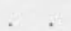 & - & . & . & . & . & $1,358,389$ & $1,778,058$ & 1.9 & 36.8 & $2,875,761$ & 3.5 & 20.1 \\
\hline Michigan & & & & . & . & . & 839,338 & $1,267,518$ & 3.0 & 23.4 & $2,818,341$ & 5.9 & 12.1 \\
\hline California & (Berl & keley & & . & . & . & 802,817 & $1,378,602$ & 3.9 & 18.1 & $2,503,060$ & 4.4 & 16.1 \\
\hline Cornell & . . & . & . & . & . & . & 877,393 & $1,206,195$ & 2.3 & 30.5 & $2,116,230$ & 4.1 & 17.3 \\
\hline Chicago & & . & . & . & . & . & $1,012,535$ & $1,584,264$ & 3.2 & 22.0 & $2,094,824$ & 2.0 & 35.0 \\
\hline Minnesota & & & . & . & . & . & 682,894 & $1,422,529$ & 5.4 & 13.2 & $1,968,101$ & 2.3 & 30.5 \\
\hline Pennsylvan & & . & . & . & . & . & 773,843 & $1,033,794$ & 2.1 & 33.3 & $1,665,114$ & 3.5 & 20.1 \\
\hline Princeton & & . & 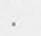 & . & . & . & 678,299 & $1,058,920$ & 3.2 & 22.0 & $1,626,537$ & 3.1 & 22.7 \\
\hline Stanford & & & . & & . & . & 567,243 & 952,051 & 3.8 & 18.6 & $1,592,287$ & 3.7 & 19.1 \\
\hline California & (Los & Ang & gele & & . & . & 191,250 & 543,281 & 7.7 & 9.3 & $1,464,308$ & 7.3 & 9.8 \\
\hline Duke . & $\therefore$. & . & . & . & . & . & 307,601 & 740,493 & 6.5 & 11.0 & $1,435,164$ & 4.8 & 14.8 \\
\hline Northweste & ern & . & . & . & . & . & 418,098 & 788,832 & 4.6 & 15.4 & $1,429,431$ & 4.3 & 16.5 \\
\hline Wisconsin & . & . & . & . & . & . & 441,500 & 600,000 & 2.2 & 31.9 & $1,384,222$ & 6.2 & 11.5 \\
\hline Ohio & . & . & . & . & . & . & 395,725 & 709,875 & 4.3 & 16.5 & $1,369,348$ & 4.8 & 14.8 \\
\hline Texas : & 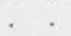 & . & . & . & . & . & 436,224 & 801,637 & 4.4 & 16.1 & $1,350,671$ & 3.8 & 18.6 \\
\hline Indiana & & . & . & . & . & . & 247,320 & 617,947 & 6.8 & 10.5 & $1,317,269$ & 5.6 & 12.7 \\
\hline Johns Hop & kins & . & . & . & . & . & 423,501 & 737,760 & 4.0 & 17.7 & $1,159,747$ & 3.3 & 21.3 \\
\hline New York & & . & & . & . & . & . & 715,157 & & & $1,067,946$ & 2.9 & 24.2 \\
\hline Washingtor & $\mathrm{n}$ (Se & eattl & & . & . & . & 316,136 & 594,320 & 4.6 & 15.4 & $1,060,086$ & 4.2 & 16.8 \\
\hline Brown &. & . & . & . & . & . & 430,683 & 665,041 & 3.2 & 22.0 & $1,025,479$ & 3.1 & 22.7 \\
\hline Iowa & . & . & . & . & . & . & 352,192 & 665,930 & 4.7 & 15.1 & $1,021,441$ & 3.1 & 22.7 \\
\hline Missouri & . . & . & . & . & . & . & 292,268 & 525,557 & 4.3 & 16.5 & $1,002,263$ & 4.7 & 15.1 \\
\hline Mean & . & . & . & . & . & . & 767,970 & $1,229,438$ & 3.4 & 20.7 & $1,989,115$ & 3.5 & 20.1 \\
\hline
\end{tabular}


TABLE 2

Growth of COLlege AND UNIVERSITY LibRaRies

(after Rider, 1940)

a) Representative Large University Libraries

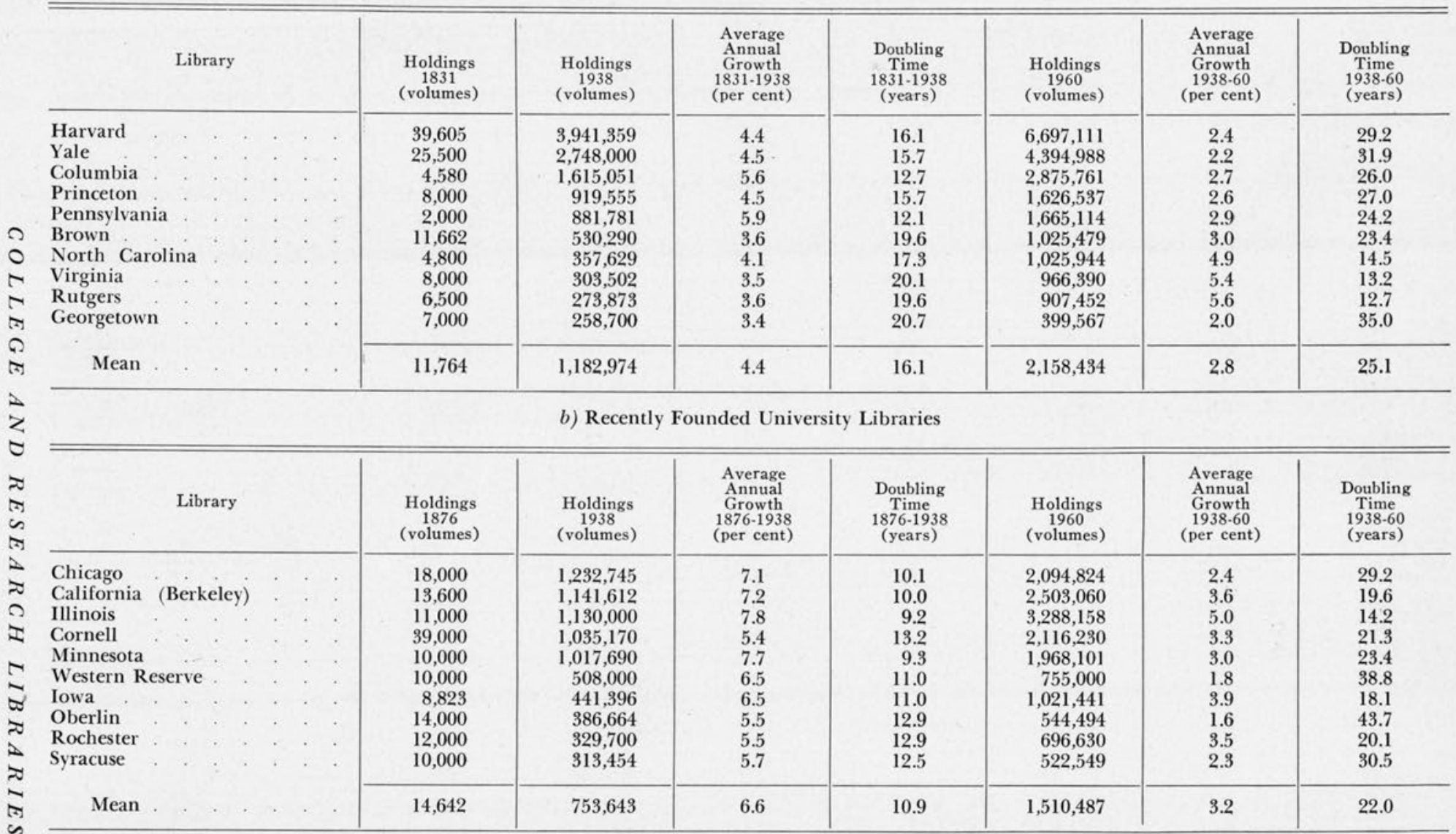


ever, that the rate of growth for a given library does or should remain invariable throughout the library's existence, or that the growth rates of all comparable libraries should be the same or closely similar, considering the great number of internal and external educational and economic factors affecting library acquisition. The commonly quoted values of fifteen, sixteen, or twenty years for "normal" or "average" or "typical" doubling times need not be accepted as such. Indeed, there appears to be no obvious reason why Rider considered fifteen or sixteen years typical. On the basis of his own computations of value thirteen years for doubling would be more typical for the twenty "university" libraries he studied.

The significance of the growth rate as a meaningful datum remains to be established. Rider's statement that “. . . we may assert this as almost axiomatic: unless a college or university is willing ... not to maintain its place in the steady flow of cultural development, it seems to be inevitable that it must double its library in size every fifteen or twenty years" ${ }^{4}$ seems to establish rate of growth as a datum independent of the basis upon which this growth occurs, i.e., the absolute size of the holdings. That is, it doesn't matter how large a library is, as long as it grows rapidly. As the size of the library increases, the annual increments necessary to support a rate of growth which will result in doubling every fifteen or twenty years become very large, and, if projected very far, become astronomical in size. This fact very likely caused Metcalf, in 1954, to say, "When a library has reached maturity ... if its book collections increase very much more than $2 \frac{1}{2}$ per cent a year, the library is growing more rapidly than it should."'5

\footnotetext{
4 Rider, op. cit., p. 11

${ }^{5}$ K. D. Metcalf, "Spatial Problems in University Libraries" Library Trends, II (1954), 559.
}

That is, if it is large enough, it need not and should not grow rapidly.

But these contradictory quotations are, after all, subjective evaluations, although made, to be sure, by eminent and respected authorities. Axford has used a more objective measure of the relevance of a library's growth rate to the academic quality of its parent institution. Using an available academic ranking of institutions offering graduate study in many fields Axford concluded that "Rider's emphasis on the positive relationship between the rate of growth of the university library and the overall quality of the educational program is still essentially correct."6 Again, questionable selection, listing, and analysis of the data appear to have lead to debatable conclusions.

Dean Haywood Keniston, in the course of an educational survey of the University of Pennsylvania ${ }^{7}$ constructed a rank order of universities based upon the excellence of their graduate teaching and research programs in the arts and sciences, as rated by a large number of graduate deans and departmental chairmen in their specialities throughout the nation's leading universities. This rating was accepted by Bernard Berelson ${ }^{8}$ as being essentially sound, and was used by him in many of the comparisons in his work, although he added the California Institute of Technology and the Massachusetts Institute of Technology to the top twenty schools, for purposes not relevant here. Keniston's study was limited to those institutions offering graduate study in a wide variety of fields.

If, however, certain rank orders of library data for the twenty institutions (omitting M.I.T. and CalTech because they have academic offerings in only a

\footnotetext{
Axford, op. cit., p. 347.

7 Haywood Keniston, Graduate Study and Research in the Arts and Sciences at the University of Pennsyl. vania. (Philadelphia: University of Pennsylvania Press, 1959).

8 Bernard Berelson, Graduate Education in the United States. (New York: McGraw-Hill, 1960).
} 
TABLE 3

Correlations Among University Academic Ranking,

LibraRy Holdings, ANd Growth RATE

\begin{tabular}{|c|c|c|c|c|c|c|c|c|c|}
\hline \multirow{2}{*}{\multicolumn{3}{|c|}{ INSTITUTION }} & \multirow{2}{*}{$\begin{array}{l}\text { Keniston- } \\
\text { Berelson } \\
\text { Rank } \\
\text { Order }\end{array}$} & \multicolumn{2}{|c|}{$\begin{array}{c}\text { LIBRARY } \\
\text { HOLDINGS } \\
1946\end{array}$} & \multicolumn{2}{|c|}{$\begin{array}{c}\text { LIBRARY } \\
\text { HOLDINGS } \\
1960\end{array}$} & \multicolumn{2}{|c|}{$\begin{array}{c}\text { Average ANNuAL } \\
\text { Growth RATE } \\
1946.60\end{array}$} \\
\hline & & & & $\begin{array}{l}\text { Million } \\
\text { Volumes }\end{array}$ & $\begin{array}{l}\text { Rank } \\
\text { Order }\end{array}$ & $\begin{array}{l}\text { Million } \\
\text { Volumes }\end{array}$ & $\begin{array}{l}\text { Rank } \\
\text { Order }\end{array}$ & Per Cent & $\begin{array}{l}\text { Rank } \\
\text { Order }\end{array}$ \\
\hline \multicolumn{10}{|l|}{ Top ten: } \\
\hline Harvard & & . & 1 & 4.80 & 1 & 6.70 & 1 & 2.4 & 17 \\
\hline California (Berl & keley) & . & 2 & 1.38 & 7 & 2.50 & 6 & 4.4 & 6 \\
\hline Columbia & . & . & 3 & 1.78 & 4 & 2.88 & 4 & 3.5 & 12.5 \\
\hline Yale & & & 4 & 3.54 & 2 & 4.39 & 2 & 1.6 & 20 \\
\hline Michigan . & & . & 5 & 1.27 & 8 & 2.82 & 5 & 5.9 & 3 \\
\hline Chicago & . & . & 6 & 1.58 & 5 & 2.09 & 8 & 2.0 & 19 \\
\hline Princeton. & . & . & 7 & 1.06 & 10 & 1.63 & 11 & 3.1 & 15 \\
\hline Wisconsin & . & . & 8 & 0.60 & 18 & 1.38 & 15 & 6.2 & 2 \\
\hline Cornell . & . & . & 9 & 1.21 & 9 & 2.12 & 7 & 4.1 & 9 \\
\hline Illinois . & . & . & 10 & 2.00 & 3 & 3.29 & 3 & 3.6 & 11 \\
\hline \multicolumn{10}{|l|}{ Second ten: } \\
\hline Pennsylvania & & . & 11 & 1.03 & 11 & 1.67 & 10 & 3.5 & 12.5 \\
\hline Minnesota & & . & 12 & 1.42 & 6 & 1.97 & 9 & 2.3 & 18 \\
\hline Stanford & & $i$ & 13 & 0.95 & 12 & 1.59 & 12 & 3.7 & 10 \\
\hline California (Los & Angele & & 14 & 0.54 & 20 & 1.46 & 13 & 7.3 & 1 \\
\hline Indiana & . & . & 15 & 0.62 & 17 & 1.32 & 17 & 5.6 & 4 \\
\hline Johns Hopkins & : & . & 16 & 0.74 & 14 & 1.16 & 18 & 3.3 & 14 \\
\hline Northwestern & 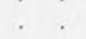 & . & 17 & 0.79 & 13 & 1.43 & 14 & 4.3 & 7 \\
\hline Ohio . & . & . & 18 & 0.71 & 16 & 1.37 & 16 & 4.8 & 5 \\
\hline New York & . & . & 19 & 0.72 & 15 & 1.07 & 19 & 2.9 & 16 \\
\hline Washington (Se & eattle) & . & 20 & 0.59 & 19 & 1.06 & 20 & 4.2 & 8 \\
\hline \multicolumn{10}{|c|}{$\begin{array}{l}\text { Correlation Coefficient } \\
\text { with Keniston-Berelson }\end{array}$} \\
\hline Rank Order & . & . & & & .76 & s & .87 & & -.24 \\
\hline
\end{tabular}

limited number of fields and relatively small libraries) are compared with the actual Keniston-Berelson rank order (Table 3) a different conclusion must be reached. The correlation between Keniston-Berelson rank order and library growth rate rank order during the last fourteen years $(r=-.24)$ is not significant. On the other hand, the correlation between the Keniston-Berelson rank order and the rank order of absolute size of library holdings is highly significant for 1946 holdings $(r=.76)$, and even more spectacularly significant for 1960 holdings $(\mathrm{r}=.87)$.

Berelson reported that he had encountered, in interview, some dispute as to the validity of the Keniston academic ranking in some specific areas.
Answering these criticisms, he reports, would result in moving a given institution one or at most two places up or down on the list, and this would make very little difference in the values of the coefficients of correlation. Whatever criticisms of the detailed ranking he encountered were obviated by using the ranking in the two clusters of top ten and second ten, and it is in this form that Berelson used it in most of his analyses. He reports almost complete agreement with the ranking as used in this way.

Using such clusters in comparing library size and growth data with academic ranking (Table 4) leads to the same conclusions as does the calculation of coefficients of correlation. The mean 
TABLE 4

Library Holdings and Growth of Graduate Study Institutions

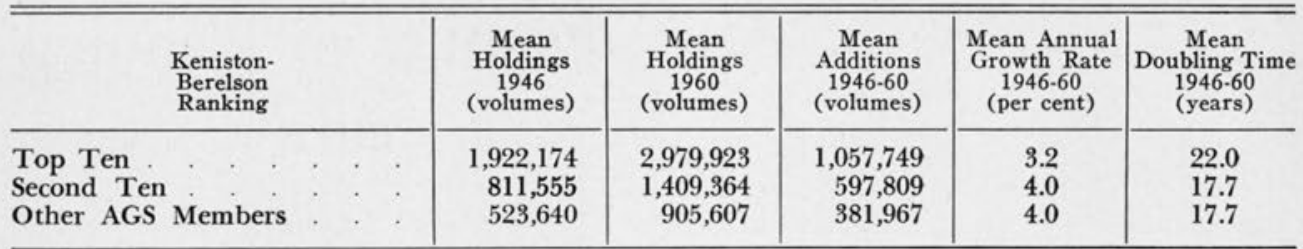

of the top ten institutions had over twice as many volumes in 1946 and 1960 as did the mean of second ten institutions and over three times as many volumes as the mean of unranked other institutions belonging to the Association of Graduate Schools. ${ }^{9}$ During the period of study the mean of top ten institutions added almost twice as many volumes as the mean of second ten institutions and almost three times as many as the mean of other unranked AGS members. At the same time, the mean growth rate of the latter two clusters was significantly higher than the growth rate of the mean top ten institutions.

This comparison is probably even more meaningful than is the comparison of rank order correlations. Not only does it avoid the minute determination and comparison of library holdings, data which are somewhat unreliable, but of even greater importance, it shows that the magnitude of yearly gross holdings additions, like the holdings themselves, are of more significance than growth rate in determining library quality.

That the absolute size of a university library's holdings and the absolute size of its yearly gross increments, and not its current growth rate, are the best measures of its quality has other confirmation, as Fussler has pointed out. ${ }^{10}$ Those large university libraries, notably

\footnotetext{
- Relevant size figures were readily available for only fourteen of these unranked institutions.

$10 \mathrm{H}$. H. Fussler, personal communication, October 5,1962 .
}

Chicago and Yale, which are carrying out weeding programs, adversely affect their growth rates thereby. At the same time, they are undoubtedly improving their libraries and they remain in the upper ranks of research institutions in spite of having very low growth rates, because they remain large libraries adding large yearly increments to their holdings. On the basis of growth rates alone they would be considered to be in sad decline.

Strong positive correlation between two sets of data does not in itself establish causal connection between them. The existence of high correlation between absolute size of library holdings and the academic quality of an institution's graduate program does not establish that the former causes the latter any more than that the latter causes the former. It does suggest strongly, however, that the two are not independent-very likely cause and effect are intertwined, as Clapp has concluded. "And just as good graduate students are attracted to good teachers, so the good scholars are attracted to institutions having good libraries. And-and this is the whole point-libraries which are good for the diversity of interests which are represented in a university faculty necessarily are or soon become large libraries.11

11 Verner Clapp, "Graduate Education and Library Resources," Journal of the Graduate Research Center (of Southern Methodist University), XXX (1962), 51. 